ECS are believed to occur in the central nervous system, these results should be regarded as evidence supporting the central mediation hypothesis.

Hebb (1949) contended that associations depend upon the continuity of electrical activity in the brain during CS-US interval. The possibility was offered of extending this conception of the associative mechanism to account for mediation of long taste-illness intervals. The sizable aversion shown by ECS-Cytoxan rats argues against such an extension. It is unlikely that ongoing electrical activity could endure ECS.

In concluding, we offer our own conception of the mediator bridging taste-illness intervals: A mechanism could exist that somehow addresses a recent taste memory permitting it to be "called up" upon report of visceral reaction. Electric shock interferes with this mechanism, reducing its efficiency in retrieving the appropriate memory at the appropriate time. The mechanism must be relatively stable judged by its remarkable resistance to electrical interierence. Garcia \& Ervin (1968) have provided impetus for such speculation by drawing attention to the close anatomical convergence of first-order fibers carrying taste and visceral information upon second-order neurons in the solitary nucleus. It may be that the addressing mechanism takes the form of a functional connectivity or convergence among these second-order cells. By virtue of anatomical proximity, the functional connectivity might be able to maintain integrity, in spite of interterence. for unusually long time periods. The rats' eating pattern serves to prevent confounding of the retrieval mechanism, while keeping interference at a low level.

\title{
Theophylline: Induction of self-biting in rabbits $^{1}$
}

LAURA L. MORGAN, NEIL SCHNEIDERMAN, and WILLIAM L. NYHAN ${ }^{2}$ University of California. San Diego, La Jolla, Calif. 92037, and University of Miami, Coral Gables. Fla. 33124

A tentative animal modcl is presented for studying the self-mutilating behavior seen in children with an abnormality of purine metabolisn. Each of four groups of
These animals typically abstain from eating for long intervals after sampling a nove] tasting meal (Rozin, 1969).

Our speculations are not intended as a theoretical statement. but are offered only because they have guided subsequent research with the interpolated shock paradigm in this laboratory: If isolation from interference preserves the integrity of the addressing mechanism, then by introducing graded amounts of artificial interference into the system (electric shock duration or intensity), the strength of the taste-illness association should be manipulated.

\section{REFERENCES} A. Learning with prolonged delay of reinforcement. Psychonomic Science, 1966, 5, 121-122.

GARCIA, J., \& ERVIN, F. R. Gustatory-visceral and telereceptor-cutane ous conditioning-adaptation in internal and external milieus. In: Communications in behavioral biology. Part A, 1. New York: Academic Press, 1968. Pp. 389-415.

GLICKMAN, S. E. Perseverative neural processes and consolidation of the memory trace. Psychological Bulletin, 1961, 58, 218-233.

HEBB, D. O. The organization of behavior. New York: Wiley, 1949.

ROZIN, P. Adaptive food sampling patterns in vitamin deficient rats. Journal of Comparative \& Physiological Psychology, 1969, 69, 126-132.

\section{NOTES}

1. This research, based on a doctoral dissertation at George Peabody College, was supported by Grant No. HD-43 of the National Institute of Child Health and Human Development, and was presented at the 10th Annual Meeting of the Psychonomic Society, St. Louis, 1969. Special thanks go to H. C. Wilcoxon and Laird W. Heal for their continued guidance and support.

2. Present address: Department of Psychology, Duke Unviersity, Durham, N.C. 27706.
GARCIA, J., ERVIN, F. R., \& KOELLING, R.

disorder of uric acid metabolism and nervous system function (Lesch \& Nyhan, 1964). The most striking aspect of the disease is self-destructive biting of the lips and fingers. Clinical symptoms also include cerebral palsy with chorea, athetosis, hypertonia, and mental retardation. The severity of the mental retardation and other behavioral effects of the Lesch-Nyhan syndrome are difficult to assess, not only because of the patient's disability, but also because of the need to keep the patient in restraints. Furthermore, ethical consideration involved with studying human patients requires the exploration of animal models for the examination of relationships between purine metabolism and behavior.

While studying the effects of caffeine toxicity in starved rats, Peters (1966) observed incidental evidence that rats receiving a reduced diet and high doses of the methylpurine caffeine show self-mutilative behavior. In studying the biochemical structure activity relationships in rats receiving another methylpurine, theophylline, McDonald, Morgan, Sage, Sweetman, \& Nyhan (in preparation) have also observed self-biting behavior. The purpose of the present experiment was to determine systematically whether or not the administraiton of theophylline would induce self-mutilation in the rabbit, an animal that, unlike the rat, does not use its teeth in aggressive behavior.

\section{METHODS}

Forty-two New Zealand male albino rabbits, weighing 1.6 to $2.9 \mathrm{~kg}$, were housed individually in wire cages and maintained ad lib on water. They were offered a quarter normal daily diet of Purina Rabbit Chow. After receiving the diet for 2 days, four groups of 10 rabbits each were given daily intraperitoneal injections of $0.15 \mathrm{~N}$ saline or $46.0,61.5$, or $92.0 \mathrm{mg} / \mathrm{kg}$ anhydrous theophylline (1,3-dimethylxanthine) in saline for 25 days. Two additional rabbits received $107 \mathrm{mg} / \mathrm{kg}$ of theophylline. Dosages were adjusted daily to compensate for weight changes. Theophylline was obtained from Mann Research Laboratories and Nutritional Biochemicals Corporation; it was added to the saline and heated until dissolved, and then cooled to body temperature before injection. Assessments of self-biting behavior were made by two independent Os.

was given a quarter-normal din daily injections of saline or 46.0,61.5, or $92.0 \mathrm{mg} / \mathrm{kg}$ of anhydrous theophylline (1,3-dimethylxanthine). The major findings were that (1) the greatest number of self-biters were found in the $61.5 \mathrm{mg} / \mathrm{kg}$ group, (2) mortality was directly related to drug dosage, and (3) the onset of biting occurred earliest with the highest dosage.

The Lesch-Nyhan syndrome is a familial

\section{RESULTS}

Percentages of rabbits showing self-biting in the saline control and theophylline groups may be seen in Fig. 1. Self-biting was observed in each of the treated groups but not in the control group. The greatest number of self-biters, 




Fig. 1. Incidence of self-multilation and incidence of deaths in rabbits treated intraperitoneally with theophylline while receiving reduced rations of food.

eight, occurred in the group receiving $61.5 \mathrm{mg} / \mathrm{kg}$ of theophylline. The number of rabbits dying during the experiment increased monotonically as a function of drug dosage. Analyses of $x^{2}$ indicated the presence of reliable $(p<.01)$ differences among groups in the number of rabbits showing self-biting and in the number of rabbits dying during the course of the experiment.

The mean number of days until self-biting occurred may be seen in Fig. 2 . No self-biting occurred in the control group. The mean numbers of days until biting occurred were $16.1,18.0$, and 5.8 dayys, respectively, in the $46.0-, 61.5-$, and $91.0-\mathrm{mg} / \mathrm{kg}$ theophylline groups. An analysis of variance in conjunction with Duncan range posttests indicated reliable $(\mathrm{p}<.05)$ differences between the control and each of the drug groups and between the $46.0-$ and $61.5-\mathrm{mg} / \mathrm{kg}$ vs the $92.0-\mathrm{mg} / \mathrm{kg}$ theophylline groups.

During the 25 days of the experiment, no deaths occurred in the saline or in the $46.0 \cdot \mathrm{mg} / \mathrm{kg}$ theophylline groups. In contrast (Fig. 2), the mean number of days until death occurred was 18.2 in the $61.5 \cdot \mathrm{mg} / \mathrm{kg}$ and 6.0 in the $92.0-\mathrm{mg} / \mathrm{kg} \mathrm{drug}$ group. An analysis of variance in conjunction with Duncan range posttests indicated the presence of reliable $(p<.01)$ differences between (a) the two highest drug-dosage groups, (b) the saline control group and each of the two highest drug-dosage groups, and (c) the 46.0-mg/kg drug group and each of the two highest drug-dosage groups.
Although $80 \%$ of the rabbits revealed self-biting in the $61.5 \mathrm{mg} / \mathrm{kg}$ drug group. the mean number of days until self-biting began was 18 . In contrast. the three rabbits showing self-biting in the $92-\mathrm{mg} / \mathrm{kg}$ drug group began after 3.0.6.0. and 9.0 day's. All three rabbits in the $92.0-\mathrm{mg} / \mathrm{kg}$ theophylline group revealed severe self-biting, whereas self-biting in the $61.5 \cdot \mathrm{mg} / \mathrm{kg}$ drug group ranged from mild to severe. Of course. others in the group might have bitten later had they survived. The relatively smaller incidence of self-biting in this group is probably attributable to the high incidence of mortality before self-biting would be expected to develop. In the $61.5 \mathrm{-mg} / \mathrm{kg}$ group, the mean number of days of injection until biting began was 18 . whereas in the $92.0-\mathrm{mg} / \mathrm{kg}$ group, no animal lived more than 13 days after injection and the mean was 6 days. Two animals given theophylline dosages of $107 \mathrm{mg} / \mathrm{kg}$ had convulsions and died with in $24 \mathrm{~h}$.

When self-biting occurred in this experiment, it generally followed a particular sequence that began with mutilation of the forepaws and progressed proximally towards the foreleg socket and abdomen. Death in the experimental animals was preceded by a marked diminution of respiratory rate and convulsions. Postmortem examination typically revealed evidence of hemmorrhage in the heart and lungs. In animals maintained on the drug for more than 2 weeks, hemorrhages were sometimes also observed in the kidneys. DISCUSSION

The major finding of this experiment was that rabbits given appropriate doses of theophylline developed self-mutilation. In this respect, the behavior induced by the administration of theophylline bears some resemblance to that observed in human children with the Lesch-Nyhan syndrome. a genetically transmitted disorder of purine metabolism.

In a study of caffeine toxicity, Peters (1966) observed tonic-clonic seizures and self-mutilation in rats. Caffeine is a methylpurine in which there are methyl groups in the 1, 3, and 7 positions. Since rats typically use their teeth in aggression, it is conceivable that the biting represents a form of self-directed aggression. However, rabbits, now found also to show self-mutilative behavior, are much less aggressive animals and usually do not use

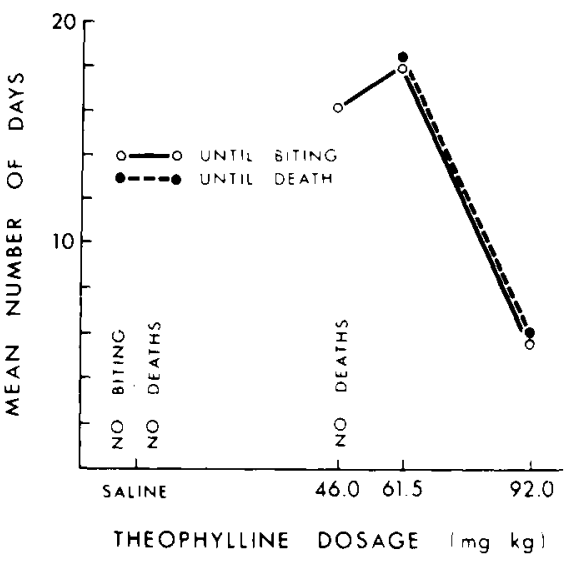

Fig. 2. Number of days from the start of the experiment until the onset of biting. and until death.

their teeth in this fashion. It appears. therefore. that this behavior is complicated. The mechanism could induce central effects in the brain or irritation of sensory nerve endings. A peripheral explanation is suggested by the findings of Luduena (1942) that theophylline causes puresthesions of the tungue. mouth. face. and upper limbs in man. On the other hand, the occurrence of convulsive death supports a central mechanism.

Gross similarities in behavior of rats. rabbits, and humans receiving methylpurines, as well as the features of the Lesch-Nyhan syndrome suggest that continued research in this area may provide insight into relationships between purine metabolism and behavior.

\section{RFIERENCES}

LESCH. M. \& NYHAN. W. L. A familial disorder of uric acid metabolism and nervous sy tem function. American Journal of Medicine, 1964. $36.501-570$.

LEDLFNA. I. P. Bronchial antispasmotic actions of theophylline derivatives including effects of continued administration. Journal of Pharmacology \& Fxperimental Therapy. 1942. 75. 316-327.

PETERS, J. M. Caffeine toxicity in starved rats. Toxicology \& Applied Pharmacology 1 1966.9. 390-397.

\section{NOTES}

1. Supported by National Science Foundation Grant GB7944 and LiSPHS Grant HD 04608 and Training Grant HD 01187 from the National Institute of Child Health and Human Development. National Institutes of Health.

2. Requests for reprints should be sent to Neil Schneiderman. Department of Psychology. University of Miami. Coral Gables. Fla. 33124 